
1996, at the same time as two paralle studies led by the ESS Scientific Coordinator (J.L. Finney of London University) on users' requirements and on instrumentation requirements and the scientific case. All three studies will report in autumn 1996 to allow time

\section{EUPRO Progresses à la carte}

The European Union for Physics Research Organizations (EUPRO) currently groups representatives of 14 organizations. It focuses its efforts on promoting à la carte cooperation among typically 3-4 member organizations on topics in mainstream physics, starting with facilities. Hans Chang, EUPRO's chairman and the Director of the Dutch funding agency FOM, told the EPS Council in Bad Honnef that following its meeting in February in Munich, EUPRO is waiting for the various member organizations to discuss the science case, cost and location of a high magnetic field facility before taking up the question of possible cooperation. A recent workshop concluded that a $100 \mathrm{~T}$ device with a pulse duration of 1 seconds is too ambitious, so proposals and futher studies are being prepared for moving in stages to 0.01 and 0.1 seconds.

Five member organizations have agreed to discuss possible cooperation in the area of free-electron lasers where four facilities - in Holland, France, Germany, and Italy have already filed a joint application for support to the European Union's Training and Mobility for Researchers programme.

Having studied the results of a second Experts Meeting organized by the OECD's Megascience Forum, synchrotron radiation facilities are no longer on EUPRO's agenda. But this is not the case for neutron sources. Several reports will appear in 1996 (see below) dealing with the scientific case and technical options for the proposed European Neutron Source (ESS). European governments and funding agencies will need to analyze them in the light of the US Department of Energy's (DoE) decision not to continue with the the large, reactor-based, Advanced Neutron Source. In line with the DoE's thinking, Dr. Chang also feels that with the renewed interest in the US for a major spallation source similar to the ESS it may be logical for European and US scientists to come together at some stage to work, for instance, on joint R\&D.

A different type of EUPRO initiative has been to approach the Brussel-based Co-operation in Science and Technology (COST) organization which includes east and central European countries among its 24 members

\section{K.H. Chang, the Director of EUPRO.}

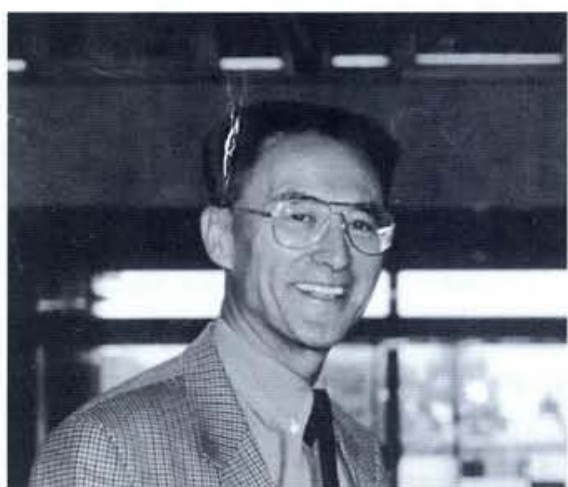

to see if technology driven physics could be funded. An ad hoc working group is presently developing concrete proposals and COST will decide in early-1996 if they can be funded as so-called COST actions.

\section{Permanent OECD Body Proposed}

The OECD's Megascience Forum was established in 1992 for three years as a subsidiary body of the organization's Committee for Science and Technology Policy (CSTP), one of 200 so-called permanent Standing Bodies, following a Ministerial-level meeting. With 23 countries participating, the Forum has operated mainly through meetings of experts to generate and distribute information in selected fields. The next CSTP Ministerial meeting in September will be asked to decide if it wants to provide a more stable arrangement for preparing Ministerial-level discussions on cooperative agreements in science. The proposal, which was agreed to by the Forum in January at its 6 th meeting and has been sent to Ministers for comment (the UK and Germany appear to object to the cost), is to have à la carte working groups set up by interested countries to discuss specific areas. The groups would be open to non-OECD countries on a case-by-case basis. The Forum has carried out very useful reviews of six fields involving large facilities and/or programmes and has identified a number of policy issues.

\section{US Reprogrammes for Spallation}

Following the US Department of Energy's (DoE) decision in February 1995 not to continue with the 3000 M\$US enriched uranium fuelled Advanced Neutron Source (ANS) reactor facility owing to its cost and the nuclear proliferation issues, the DoE has indicated that its aims have been "reprogrammed". It is now thinking in terms of a $5 \mathrm{MW}$ pulsed spallation source (tentatively called PSNS) with the Oak Ridge National Laboratory (the proposed ANS site) as the preferred site. There is a "chance" it could be constructed because the US lacks a large neutron source of the Institut Laue-Langevin class (indeed, a 1993 US review recommended the ANS and a spallation source). With the US President's budget request seeking 8 MSUS for design activity, there should be collaboration with other laboratories active in the field. These are the Los Alamos National Laboratory (which seeks an upgrade to the world's most powerful powerful proton accelerator LAMPF), Argonne National Laboratory and the Brookhaven National Laboratory (1-5 MW short pulse spallation sources proposed), and the Berkeley National Laboratory (which is studying, among other things, an $\mathrm{H}^{-}$source). The DoE also seems to be interested in collaborating with Europe on R\&D for future spallation sources.

A technical study of the proposed $5 \mathrm{MW}$ European Spallation Source (ESS) under $\mathrm{H}$. Lengeler from CERN, the ESS Project Leader, is being supervised by the ESS to prepare an application to the next European Union Framework Programme.

Specialists are presently analyzing options and scientific developments. It is unclear at what stage and at which level international discussions could take place once the European studies come together in 1996.

\section{Nuclear Council to be Considered}

One of the themes running through discussions of ways to coordinate better the promotion of new facilities involves creating a partnership between scientists and government administrators. The conclusions of a meeting entitled International Cooperation in Nuclear Physics (Amsterdam, 8-9 December 1994) organized by Herman Feshbach from MIT who chairs IUPAP's International Committee for High Intensity Accelerators (ICHIA: see EN, Sept. 1994, p. 156) indicated that there is some resistance to the proposal to form a Forum of Senior Administrators with an advisory group of scientists. This mainly comes from the concern that international-level discussions involving administrators may affect both national programmes and regional coordination through bodies such as the Nuclear Physics European Coordination Committee (NUPECC).

The fact that as many as 23 countries sent representatives to the Amsterdam meeting confirms that the future of nuclear physics lies in international cooperation. So governments will have to be involved. The meeting thus voted unanimously to consider an International Council for Nuclear Science which would include administrators. A second meeting to be held in conjunction with the 18th International Conference on Nuclear Physics (Beijing, 22-26 August 1995) will aim to articulate the arguments for the Council. One first needs to establish who can appoint such a body, its composition, to whom it reports, and how its agenda is decided Several models of frameworks for international cooperation were discussed, including the US Neutron Science Advisory Committee (a committee of scientists chosen by and reporting to the Department of Energy), NUPECC (an Associated Committee of the European Science Foundation appointed by the ESF Executive Council) and the CERN Council (comprising an administrator and a

\section{H. Feshbach, the Chairman of ICHIA.}

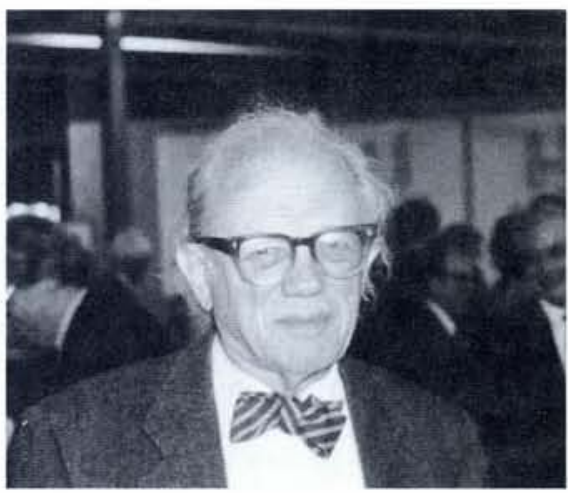


scientist from each CERN Member State).

Professor Feshbach thinks possible extremes are a IUPAP body or what he calls "a new paradigm" based on a working group of scientists and administrators appointed by the OECD (such working groups will be decided upon by the OECD next September as a follow-on to its Megascience Forum - see above). He believes physical societies would naturally be responsible for appointing scientific members, a role that is fully endorsed by Renato Ricci who chairs the EPS Nuclear Physics Division. National bodies related to the societies and to specific institutions could provide useful interfaces through channels such as NuPECC and the EPS Nuclear Physics Division Board. It seems that this would be very important for generating concrete and efficient East-West relationships - an issue that will be discussed at the next meeting of the Board during the 15th Divisional Conference Low-Energy Nuclear Dynamics (LEND'95) in St. Petersburg on 18-22 April 1995.

\section{AARHUS UNIVERSITET, DENMARK}

Professorship in Experimental SolidState Physics (Reference No.: 211/5-8)

Owing to a delay for advertising in Europhysics News, the closing date for applications for the above position has been extended to twelve noon, 1 August 1995. The position was originally advertised in the January/February 1995 issue of Europhysics News.

\section{NATO Advanced Study Institute \\ HADRON SPECTROSCOPY \& THE CONFINEMENT PROBLEM}

27 June - 7 July 1995 - Swansea, Wales

Participation is limited to 70 students. Cost $£ 560$-, incl. full board. Studentships available, with special support for students from Greece, Portugal and Turkey.

Contact: D.V. Bugg, DRAL, Chilton, Oxon OX11 OQX, UK. Tel.: +44-1235-44 5567 Fax: +44-1235-44 67 33;

e-mail: bugg@v2.rl.ac.uk

\title{
THE NETHERLANDS
}

\section{Pressure On Research from Several Sides}

\author{
Huub Eggen of the Dutch funding agency FOM reports on factors affecting physics \\ research in The Netherlands, including financial cuts.
}

The Dutch Prime Minister who came into office last August is well known for his outspoken views on education and research. While basic education is considered vital, higher education has less support and research is sometimes viewed as an overhead. His government decided to cut funding for the higher education system (universities, polytechnics and schools of higher education) by an amount rising to $500 \mathrm{MHFL}$ starting in 1998. This aroused much concern and massive student protests. After fierce negotiations and parliamentary debate it was decided in February that higher education will only have to bear one-half of the proposed cut, that a part will be postponed until after the year 2000, and that another part can be avoided through increasing efficiency and improving curicula so that students spend less time in the system. A part of the cut will be covered by increasing the fee students pay each year.

According to a recent report of a government review panel, university spending on physics research was about 205 MHFL in 1993. Teaching staff carry out research in Holland so research will be affected by the cuts in the university budget. There will also be a shift of students from universities to polytechnics, which are cheaper (for students). Combined with demographic changes, university student numbers will probably decrease by $10 \%$ in $1995 / 6$. Overall, university expenditure on physics research is expected to go down by $5 \%$ in $1994-99$.

\section{FACILITIES IN PHYSICS: A Users Directory}

The EPS is carrying out a survey of users facilities in physics with financial support from the European Commission and in collaboration with the OECD Megascience Forum. Some $60 \%$ of questionnaires sent out in February have been returned so far. Preliminary results indicate, for instance, that the percentage of external users is proportional to the total number of users for large facilities. Facilities which have not yet replied are being contacted again. The survey is being carried out by E.W.A. Lingeman (tel. +31-20-592 21 17; e-mail: ed@nikhef.nl).

The forthcoming deadline for applicants for magnet time allocation (September 1995 to February 1996) at the

\section{GRENOBLE HIGH MAGNETIC FIELD LABORATORY}

\section{is 26 May 1995.}

Scientists from European Union countries are entitled to apply under the "Access to research under high-magnetic fields" programme. Application forms are available on request.

Please contact: J.C. VALLIER

Laboratoire des Champs Magnétiques Intenses,

Max-Planck-Institut für Festkörperforschung et

Centre National de la Recherche Scientifique

B.P. 166 - 38042 Grenoble Cedex 9 - FRANCE

Tel.: +3376881001

Fax: +3376 855610

Email: vallier@ccalc.grenet.fr
Regarding non-university spending, FOM (the principle funding agency for physics) receives about 90 MHFL from the science and technology funding agency NWO for running costs and about 7 MHFL for investments. There are also funds from other sources giving a total of about $130 \mathrm{MHFL}$ in 1995 , which is roughly the same as last year (35-40\% is spent on research in universities). But the amount will decrease by about 2 MHFL p.a. in the coming years owing to adjustments within NWO. Parliament has resisted the cabinet's proposal to reduce the funds for agencies such as NWO so it is unclear if the overall NWO budget will decrease.

The NWO runs programmes of its own, including several physics projects giving a total NWO expenditure for physics research of about $145 \mathrm{HFL}$ in 1995. This is a lower limit since physics research is also funded from outside NWO.

One concludes that non-university government funding for physics research will decrease by several percent in the years to come.

Government and industry together spend about 11000 MHFL each year on R\&D (where government spending is $4900 \mathrm{MHFL}$ in 1995). In terms of GNP, industry spending was $1.0 \%$ in 1993 , down from $1.2 \%$ in 1987 , while government spent $0.8 \%$ and $1 \%$, respectively. So the reduction in government support for research via the universities and funding agencies comes at a time when industry is cutting its spending.

Reflecting an international trend, there is also increasing political pressure on the academic system (institutes and universities) to do research which answers the needs of society in general and of industry in particular. The government will try to find ways for the universities and industry to collaborate. How this will done is unclear. Financial rewards are being considered and the economics ministry already has a fiscal model to reduce income taxes for employees involved in R\&D. Organizations such FOM would be able to profit from such measures.

The country's shift towards special, strategic R\&D programmes continues. A government-funded ( $30 \mathrm{MHFL}$ for five years) highperformance computing programme was launched in 1994 and the NWO funds a 10 MHFL companion programme (run by FOM) dealing with the scientific aspects. Materials research is receiving more attention with in addition to NWO's own programme of 2 MHFL p.a., a programme of some 25 MHFL over five years to be funded by the NWO and by the ministries of economic affairs and education. 